Article

\title{
Beliefs about Child-Rearing and Development in Spain and Peru. A Comparative Analysis for Adapting Parenting Support Programs
}

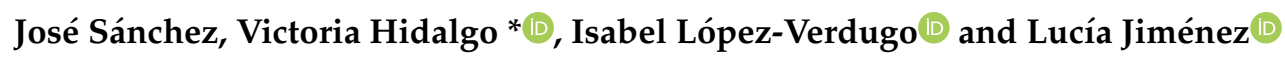 \\ Faculty of Psychology, University of Seville, 41018 Seville, Spain; js@us.es (J.S.); ilopez@us.es (I.L.-V.); \\ luciajimenez@us.es (L.J.) \\ * Correspondence: victoria@us.es
}

Received: 22 July 2020; Accepted: 1 September 2020; Published: 4 September 2020

check for updates

\begin{abstract}
Migrant families who settle in host cultures may find themselves in situations of vulnerability which hinder the exercise of their parental responsibilities. While there are many support programs targeted at these families, they are $\mathrm{n}$ ot always sensitive to the acculturation process. This article compares beliefs about child-rearing and development in Spain and Peru, with the aim of enabling interventions to be adapted to the cultural characteristics of Peruvian families living in Spain. To this end, 43 Spanish and 39 Peruvian professionals and parents participated in a Delphi process, in which they ranked issues corresponding to four topics: child and adolescent needs, functions of the family context, functions of the school context, and the value of childhood and adolescence for society. The results revealed many similarities and some differences between the cultural parenting knowledge of Spanish and Peruvian families. The implications of these results for adapting parenting support programs to migrant Peruvian families are discussed. Specifically, the article concludes that Peruvian families require special support in two areas: establishing rules and limits for children and parental involvement in the school, both of which are key aspects for promoting parenting practices which are better adapted to the families' new cultural context.
\end{abstract}

Keywords: beliefs about child-rearing and development; culture; migration; parenting support programs

\section{Introduction}

Parenting support programs have become a fundamental resource in all countries, and are widely used to promote positive parenting, particularly in the case of families in situations of vulnerability and risk [1]. These programs focus on parental beliefs and practices, with the aim of promoting sustainable development in childhood and adolescence [2,3]. Although they are designed and widely used in more developed countries, the beneficiaries of the interventions are often migrant families from developing countries with different cultural backgrounds [4]. Ignoring the cultural influences that characterize the parental beliefs and practices of these families constitutes a major risk that threatens the effectiveness of the interventions [5]. Within this framework, the aim of the present study was to explore cultural differences linked to parenting, in order to enable interventions for migrant families to be adapted to their cultural characteristics.

Although general cultural influences on parenting have been widely studied, specific analyses of how key aspects affect parenting styles and practices are complicated, because culture is, in part, shaped by socioeconomic status and other neighborhood and contextual factors [6]. One often-studied pathway through which culture influences parenting is through the beliefs and behavioral patterns acquired during the socialization process, which in turn generate a large degree of diversity among different social groups [7]. Moving away from Baumrind's classic model of parenting styles and 
how they affect children's adjustment, recent approaches are based more on domain-specific models, positing that parents adapt their parenting practices in accordance with how they interpret the cultural environment in which they find themselves. Thus, for these models, the effects of parenting on children's development may be mediated or moderated by the values, standards and customs of a particular society at a specific time in history [8]; or in other words, by aspects which make up parenting cultural knowledge.

Parenting cultural knowledge is defined as the set of beliefs held by parents regarding child-rearing and development processes throughout childhood and adolescence [9]. These parental beliefs are important for family life, because they are part of the determinants of parenting practices and influence children's development. However, these values, standards and beliefs are not simply constructed individually by each parent; to a large extent, they are also constructed by each generation and each cultural group, based on the value attached to childhood and adolescence for the construction of society. Thus, socialization processes are not simply an exercise in the transmission of information from parents to children. Rather, one of their main functions is to prepare children to be become active members of their social reference group and to construct cultural values, beliefs and customs which are adapted to the specific moment and the specific scenario in which they will live as adults [10].

From this perspective, parenting is understood as something which takes place in a specific cultural environment at a given historical moment. Thus, a family socialization model which is appropriate in one region of the planet may not be adequate somewhere else, and those employed by past generations may not be suitable today [11-13]. Parenting cultural knowledge provides parents with a framework for interpreting their children's behavior, guides their interactions with them, determines their activities, and influences the value and functions attached to different development contexts, such as the family and the school, in terms of sustainable development in childhood and adolescence [14].

Many studies currently link beliefs about child-rearing and culture, trying to identify both similarities and differences between different cultural contexts. Most of these studies are descriptive in nature and focus on highlighting how each culture fosters certain beliefs and values, while rejecting others which are not deemed useful or are considered to go against predominant cultural patterns. Thus, although it is unclear how exactly culture molds beliefs and values, it does seem apparent that different cultural forms are associated with different ways of understanding parenting, and therefore different models of childhood [8,15-19].

One of the most widely studied aspects linked to differences in parenting cultural knowledge is the way that childhood needs are understood, specifically the value attached by parents to their children's independence. There is a fairly large body of evidence to suggest that "collectivist" cultures, such as those found in Latin America and Japan, for example, value interdependence more highly, thereby fostering greater behavioral control $[20,21]$. "Individualistic" cultures, on the other hand, such as those found in North America or Central Europe, attach more importance to autonomy and self-confidence during the socialization process, with parents tending to be more permissive [22]. Thus, while in the United States and Central European countries, parents tend to promote their children's independence and facilitate their exploration of and interest in everything which surrounds them; in other cultural environments, such as Japan or Argentina, for instance, more emphasis is placed on interdependence between family members, since this is considered more beneficial for children's development [20]. These cultural differences may explain the results found in relation to the parenting styles which best predict child and adolescent adjustment in different countries. Specifically, evidence suggests that, in countries such as Spain, Portugal and Brazil, children of indulgent parents whose parenting style is characterized by low levels of coercion and high levels of affection, have adjustment levels that are equivalent to and, in certain personal and emotional dimensions, even higher than those of children of authoritative parents $[17,19,23,24]$.

The studies carried out by Keller and her teams [25] propose three cultural models of parenting, in accordance with different sets of values, socialization goals and parental theories: independent, 
interdependent and autonomous-related. The independent model is the most common in developed countries such as the United States and those in Central and Northern Europe, and is characterized by values and socialization goals based on self-confidence and competitiveness for promoting financial and emotional independence. The interdependent model, typical of subsistence-based contexts such as Cameroon and India, fosters values such as obedience, respect and family loyalty, with the aim of facilitating the working of the hierarchical system, contributing to harmonious social and family functioning and promoting the financial and emotional dependence of family members. Finally, the autonomous-related model is more common in developing regions, such as Latin American countries, which have a strong cultural inheritance based on interdependence. This model fosters both autonomy and family belonging and inclusion, promoting both financial independence and emotional dependence at the same time [25,26]. In accordance with this proposal, Kast, Farkas and Vallotton [27] found patterns of parental ideas and parenting styles linked to the autonomous-related model in Chile. According to these authors, in that country, more "traditional" parenting beliefs and practices associated with financial support and the exercise of authority currently coexist with more "modern" outlooks, which include affection as a key dimension.

If we focus our analysis on the specific contents of parental ideas and beliefs about child-rearing, the main cultural differences are found in the following areas: the use of physical punishment [28], more prevalent in cultural contexts in which aggressiveness is more accepted; the promotion of children's autonomy, more common in Central Europe and North America than in Southern Europe and Latin America [29,30]; the role at play in child development [31], with play being understood as an opportunity for learning by European and North American families, and considered a simple distraction for children in Latin America; and finally, parental expectations regarding their own influence on their children's development, which are higher among European and North American families than among Asian ones [32-35].

Currently, analyses of the influence of cultural patterns on parental beliefs and practices are also linked to the migratory phenomenon. Integrating into a new culture involves a major effort and many changes for any individual, but the challenge is even stiffer if this must also be done in relation to cognitions about parenting. Parents who move to a new cultural context are forced to undergo a process of parental acculturation, which generally involves personal adaptation and specifically demands that they adjust the parental beliefs and practices developed as part of their personal identity in their native culture to those which prevail in their new cultural context $[36,37]$.

As stated earlier, each culture has its own specific beliefs and guidelines regarding the role played by the family in child-rearing, which are transmitted from generation to generation. Thus, bringing up a child in a culture different from one's own forces parents to question their parenting beliefs and values, which will very likely impact the way in which they bring up their children $[25,36]$. However, parental acculturation cannot be analyzed as a single phenomenon which occurs in one direction only and which has a specific set of consequences, since it depends as much on pre-migration aspects such as cultural values in individuals' country of origin and reasons for migrating [38,39], as on post-migration issues, such as the migration policies in effect in the host country, and the living conditions of the various members of the family unit [20].

Today, many migrant families find themselves in situations of psychosocial risk and need support in order to ensure adequate parenting. This support is provided by the local authorities through family intervention programs, which do not always take the parenting cultural knowledge of these families into consideration. In Spain, the majority of migrant families come from Latin America, since after the United States, Spain is the country with the second highest number of migrants from this region, being the destination of approximately $8 \%$ of all emigrants who have left Latin America over the last decade [40]. Specifically, in 2019, migrants from Peru represented almost 18\% of all foreign residents in Spain [41]. Most Peruvian families in Spain are beneficiaries of parenting support programs which are not adapted to their cultural characteristics, despite the fact that existing data highlight the importance of adapting these interventions to improve their effectiveness [42]. 
In light of the above, the aim of this study was to compare parenting cultural knowledge in Spain and Peru, exploring beliefs about child and adolescent needs, the functions of the family and school contexts, and the value of childhood and adolescence for society. We hope that gaining greater insight into the cultural differences which exist between the two countries in terms of beliefs about child-rearing and development will help adapt the parenting support interventions provided to Peruvian families living in Spain, thereby improving their effectiveness.

\section{Materials and Methods}

A Delphi survey was carried out to explore the differences which exist between Spain and Peru in terms of beliefs about child-rearing and development. The survey covered two areas: the South of Spain and the Peruvian Amazon.

Following the recommendations made by Delbecq, Van de Ven, and Gustafson [43], the inclusion of the most qualified subjects to explore the beliefs about child-rearing and development in each cultural context was guaranteed by paneling, with parents and professional experts in the topic being explored. Consequently, three panels of experts were constituted, comprising: (1) community leaders on childhood and family-related topics, in particular, decision-makers and practitioners of family care services with university studies in the area of social sciences, (2) school teachers from the region, and (3) parents participating in a group parenting support program aimed at promoting parenting skills, led by a family support practitioner using structured activities through a psycho-educational and community-based methodology. Following Delbecq et al.'s recommendations regarding sample size [43], 15 experts from each panel and each location were invited to participate in the Delphi process, the only exception being community leaders from Peru, as only 9 experts in the region met the eligibility criteria. Two parents in Spain declined to remain in the study in the second round, and had to be eliminated from the analyses. The final sample, outlined in Table 1, therefore comprised 82 experts. The panel of community leaders was composed in the case of Spain of 7 women and 8 men, with an average age of 47.92 years. In the case of Peru, the community leaders were 4 women and 5 men, and their average age was 50.11 years. The panel of schoolteachers was composed in the case of Spain of 9 women and 6 men, with an average age of 46.17 years. In the case of Peru, the schoolteachers were 13 women and 2 men with an average age of 40.20 years. Finally, the Spanish parents were 9 women and 4 men, with an average age of 41.85 years. In the case of Peru, the parents were 13 women and 2 men, and their average age was 35.00 years.

Table 1. Panels of experts $(\mathrm{N}=82)$.

\begin{tabular}{cccc}
\hline & $\begin{array}{c}\text { Spanish } \\
\text { Sample }\end{array}$ & $\begin{array}{c}\text { Peruvian } \\
\text { Sample }\end{array}$ & $\begin{array}{c}\text { Eligible } \\
\text { Criteria }\end{array}$ \\
\hline $\begin{array}{c}\text { Community } \\
\text { leaders }\end{array}$ & 15 & 9 & $\begin{array}{c}\text { Managerial position as a community leader for at least 10 years } \\
\text { Proven knowledge of childhood and family-related topics }\end{array}$ \\
\hline School teachers & 15 & 15 & $\begin{array}{c}\text { Minimum of 10 years' experience as a schoolteacher } \\
\text { Managerial position in education for at least 10 years }\end{array}$ \\
\hline Parents & 13 & 15 & $\begin{array}{c}\text { School-aged children or adolescents in their care } \\
\text { Participants in parenting support programs }\end{array}$ \\
\hline
\end{tabular}

\subsection{Instruments}

The Delphi survey comprised questions on beliefs about child-rearing and development, and encompassed the following specific topics: (1) child and adolescent needs, (2) functions of the family context, (3) functions of the school context, and (4) the value of childhood and adolescence for society. Four academic experts on developmental and educational psychology composed 3 items for each topic, obtaining an initial pull of 48 questions. A hierarchy format was adopted, meaning that, for each category, panelists were asked to rank the items in order of relevance (from most to least important). 
Following the American Educational Research Association (AERA), the American Psychological Association (APA) and the National Council on Measurement in Education (NCME) recommendations [44], this initial version of the survey then underwent a refinement process. Each item was evaluated by a panel of four academics for: readability, adequacy of the vocabulary, relationship with the global construct, and pertinence concerning the specific topic. Following this process, 16 items were deleted, and the resulting 32-item version (8 for each topic) was piloted with three parents, two schoolteachers and one community leader in Spain. Some reading comprehension problems were detected, and as a result, both the instructions and six of the items were redrafted. Finally, two developmental-educational psychologists with experience cooperating with Peru culturally adapted the language for the Peruvian version. The contents included in the final version are presented in Table 2.

Table 2. Delphi contents concerning beliefs about child-rearing and development.

\begin{tabular}{cc}
\hline Topic & Contents \\
\hline Be stimulated \\
1. Child and adolescent needs \\
Feel loved and cared for \\
Go to school \\
Grow up healthy
\end{tabular}

\subsection{The Delphi Process}

The recruitment process for all participants was carried out through the family care centers in each of the two areas where the study was carried out. Two members of the research team visited the schoolteachers and community leaders at their workplaces, and parents were contacted at the family care facility where the parenting support program was delivered. The instrument was self-administered, although a verbal explanation of the study and the rating scales were provided.

During the first round, the original survey was administered, and the information obtained was summarized by the researchers. For the purposes of statistical analysis, mean values were used to integrate the scores [45]. During the second round, each expert was asked to review the integration, expressing their agreement/disagreement on a 4-point Likert-type scale (from $1=$ Completely agree to $4=$ Completely disagree). In the event of partial or total disagreement, panelists were asked to explain their reasons and make suggestions for modifications. A consensus of over $80 \%$ was the stop criterion adopted [46]; two iterations were therefore required before the process was considered complete. 


\subsection{Data Analysis}

Means were computed separately for each country in order to rank each topic; standard deviations were also provided as a complementary descriptive statistic. To check for significant intra-country differences in the ranking positions, repeated measures ANOVAs were conducted for each nearest pair of items. To check for significant inter-country differences, a MANOVA was carried out for each topic, with country as the independent variable, followed by the corresponding ANOVAs. The partial $\eta 2$ coefficient was used as an effect size measure, with $<0.01$ being considered negligible, $\geq 0.01$ and $\leq 0.05$ small, $\geq 0.06$ and $\leq 0.15$ medium, and $\geq 0.16$ large.

\section{Results}

The ranking for child and adolescent needs is shown in Table 3. The rankings were fairly similar in both countries, although differences were observed for rules, health and school. Intra-country comparisons revealed differences in Spain for the following pairs: love-rules $(F(1,42)=37.84, p<0.001$, partial $\left.\eta^{2}{ }_{1}=0.47\right)$ and play-school $\left(F(1,41)=9.98, p=0.003\right.$, partial $\left.\eta^{2}=0.20\right)$. In Peru, differences were observed for love-health $\left(F(1,38)=10.64, p=0.002\right.$, partial $\left.\eta^{2}=0.22\right)$, health-stimulation $(F(1,38)=12.62$, $p=0.001$, partial $\left.\eta^{2}=0.25\right)$ and rules-independence $\left(F(1,38)=37.84, p<0.001\right.$, partial $\left.\eta^{2}=0.50\right)$. The inter-country comparison revealed that Spain and Peru differed in their ranking of child and adolescent needs $\left(F(8,72)=6.08, p<0.001\right.$, partial $\left.\eta^{2}=0.40\right)$, and subsequent ANOVAs revealed that this difference was explained by rules $\left(F(1,79)=23.19, p<0.001\right.$, partial $\left.\eta^{2}=0.23\right)$, health $(F(1,79)=$ $13.16, p=0.001$, partial $\left.\eta^{2}=0.14\right)$, school $\left(F(1,79)=6.20, p=0.015\right.$, partial $\left.\eta^{2}=0.07\right)$ and independence $\left(F(1,79)=4.71, p=0.033\right.$, partial $\left.\eta^{2}=0.06\right)$.

Table 3. Child and adolescent needs.

\begin{tabular}{ccccccccc}
\hline & $\mathbf{1}$ & $\mathbf{2}$ & $\mathbf{3}$ & $\mathbf{4}$ & $\mathbf{5}$ & $\mathbf{6}$ & $\mathbf{7}$ & $\mathbf{8}$ \\
\hline Spain & Love & Rules & Stimula. & Health & Interacti. & Play & School & Indepen. \\
$M$ & 7.44 & 5.4 & 5.14 & 4.77 & 4.7 & 4.31 & 2.98 & 2.33 \\
$(S D)$ & $(1.28)$ & $(1.54)$ & $(1.91)$ & $(2.23)$ & $(1.68)$ & $(1.76)$ & $(2.00)$ & $(2.09)$ \\
Peru & Love & Health & Stimula. & Interacti. & School & Play & Rules & Indepen. \\
$M$ & 7.51 & 6.28 & 4.9 & 4.31 & 4.02 & 3.77 & 3.72 & 1.49 \\
$(S D)$ & $(1.25)$ & $(1.57)$ & $(1.79)$ & $(1.28)$ & $(1.84)$ & $(1.77)$ & $(1.59)$ & $(1.30)$ \\
\hline
\end{tabular}

In relation to the functions of family context, minor differences in ranking positions were observed between Peru and Spain for healthy growth, stimulation and reasoning (see Table 4). Intra-country comparisons revealed differences in Spain for the following pairs: stimulation-healthy growth $\left(F(1,41)=13.57, p=0.001\right.$, partial $\left.\eta^{2}=0.25\right)$, socialization-civic behavior $(F(1,41)=16.44$, $p<0.001$, partial $\left.\eta^{2}=0.29\right)$, reasoning-employability $\left(F(1,40)=13.04, p=0.001\right.$, partial $\left.\eta^{2}=0.25\right)$, and employability-knowledge $\left(F(1,40)=5.60, p=0.023\right.$, partial $\left.\eta^{2}=0.12\right)$. In Peru, differences were observed for stimulation-socialization $\left(F(1,38)=24.56, p<0.001\right.$, partial $\left.\eta^{2}=0.29\right)$, civic behavior-employability $\left(F(1,38)=7.39, p=0.01\right.$, partial $\left.\eta^{2}=0.16\right)$, and reasoning-knowledge $(F(1,38)=36.10, p<0.001$, partial $\left.\eta^{2}=0.49\right)$. The inter-country comparison revealed significant differences between Peru and Spain $\left(F(8,71)=3.61, p=0.001\right.$, partial $\left.\eta^{2}=0.29\right)$ in the following categories: healthy growth $(F(1,78)=10.21$, $p=0.002$, partial $\left.\eta^{2}=0.12\right)$, socialization $\left(F(1,78)=4.00, p=0.049\right.$, partial $\left.\eta^{2}=0.05\right)$ and reasoning $\left(F(1,78)=15.39, p<0.001\right.$, partial $\left.\eta^{2}=0.17\right)$. 
Table 4. Functions of the family context.

\begin{tabular}{ccccccccc}
\hline & $\mathbf{1}$ & $\mathbf{2}$ & $\mathbf{3}$ & $\mathbf{4}$ & $\mathbf{5}$ & $\mathbf{6}$ & $\mathbf{7}$ & $\mathbf{8}$ \\
\hline Spain & Protecti. & Stimula. & Healthy & Socializ. & Civic b. & Reasoni. & Employ. & Knowle. \\
$M$ & 6.98 & 6.76 & 5.50 & 5.21 & 4.02 & 3.78 & 2.60 & 1.80 \\
$(S D)$ & $(1.46)$ & $(1.26)$ & $(1.90)$ & $(1.30)$ & $(1.77)$ & $(1.46)$ & $(1.65)$ & $(1.58)$ \\
Peru & Protecti. & Healthy & Stimula. & Socializ. & Civic b. & Employ. & Reasoni. & Knowle. \\
$M$ & 6.95 & 6.69 & 6.33 & 4.59 & 4.05 & 3.02 & 2.67 & 1.69 \\
$(S D)$ & $(0.94)$ & $(1.49)$ & $(1.40)$ & $(1.50)$ & $(1.57)$ & $(1.68)$ & $(1.03)$ & $(0.95)$ \\
\hline
\end{tabular}

Concerning the functions of the school context, a fairly similar pattern was found for both countries, although minor ranking differences were observed for reasoning, socialization, civic behavior and knowledge (see Table 5). Intra-country comparisons revealed differences in Spain for the following pairs: stimulation-reasoning $\left(F(1,41)=9.18, p=0.004\right.$, partial $\left.\eta^{2}=0.18\right)$, knowledge-employability $\left(F(1,41)=12.84, p=0.001\right.$, partial $\left.\eta^{2}=0.24\right)$, and protection-healthy growth $(F(1,42)=21.48, p<0.001$, partial $\left.\eta^{2}=0.34\right)$. In Peru, differences were only observed for stimulation-socialization $(F(1,38)=22.35$, $p<0.001$, partial $\left.\eta^{2}=0.37\right)$ and protection-healthy growth $\left(F(1,38)=9.52, p=0.004\right.$, partial $\left.\eta^{2}=0.20\right)$. The inter-country comparison revealed no differences in the mean scores obtained by Peru and Spain for the functions of the school context $(F(8,71)=1.68, p=0.117)$.

Table 5. Functions of the school context.

\begin{tabular}{ccccccccc}
\hline & $\mathbf{1}$ & $\mathbf{2}$ & $\mathbf{3}$ & $\mathbf{4}$ & $\mathbf{5}$ & $\mathbf{6}$ & $\mathbf{7}$ & $\mathbf{8}$ \\
\hline Spain & Stimula. & Reasoni. & Socializ. & Civic b. & Knowle. & Employ. & Protecti. & Healthy \\
$M$ & 7.05 & 5.90 & 5.46 & 4.81 & 4.78 & 3.65 & 3.35 & 2.21 \\
$(S D)$ & $(1.68)$ & $(1.60)$ & $(1.59)$ & $(1.89)$ & $(2.27)$ & $(1.95)$ & $(1.97)$ & $(1.77)$ \\
Peru & Stimula. & Socializ. & Reasoni. & Knowle. & Civic b. & Employ. & Protecti. & Healthy \\
$M$ & 6.82 & 5.00 & 4.82 & 4.51 & 4.44 & 4.10 & 3.62 & 2.74 \\
$(S D)$ & $(1.65)$ & $(1.76)$ & $(2.05)$ & $(2.33)$ & $(1.67)$ & $(2.04)$ & $(2.02)$ & $(2.52)$ \\
\hline
\end{tabular}

Finally, the results for the value of childhood and adolescence for society are presented in Table 6. The patterns observed for this topic in the two countries were fairly similar, with minor differences in ranking positions being found only for future and vulnerable period. Intra-country comparisons revealed differences in Spain for the following pairs: prosperity-cultural transmission $\left(F(1,41)=15.58, p<0.001\right.$, partial $\left.\eta^{2}=0.28\right)$, cultural transmission-parental need $(F(1,41)=15.86$, $p<0.001$, partial $\left.\eta^{2}=0.28\right)$, and parental need-family definition $\left(F(1,42)=29.64, p<0.001\right.$, partial $\eta^{2}=$ 0.41). In Peru, differences were observed only for prosperity-cultural transmission $(F(1,38)=15.78$, $p<0.001$, partial $\eta^{2}=0.29$ ). The inter-country comparison revealed differences between Peru and Spain in the value of childhood and adolescence for society $\left(F(8,72)=2.92, p=0.007\right.$, partial $\eta^{2}=0.24$ ), explained only by family definition $\left(F(1,79)=10.42, p=0.002\right.$, partial $\left.\eta^{2}=0.12\right)$.

Table 6. Value of childhood and adolescence for society.

\begin{tabular}{ccccccccc}
\hline & $\mathbf{1}$ & $\mathbf{2}$ & $\mathbf{3}$ & $\mathbf{4}$ & $\mathbf{5}$ & $\mathbf{6}$ & $\mathbf{7}$ & $\mathbf{8}$ \\
\hline Spain & Future & Vulnera. & Moral d. & Predicts & Prosper. & Cultural & Parental & Family \\
$M$ & 6.37 & 6.05 & 6.05 & 5.42 & 5.00 & 3.69 & 2.56 & 1.35 \\
$(S D)$ & $(1.83)$ & $(1.59)$ & $(1.58)$ & $(1.84)$ & $(1.53)$ & $(1.35)$ & $(1.38)$ & $(1.13)$ \\
Peru & Vulnera. & Future & Moral d. & Predicts & Prosper. & Cultural & Parental & Family \\
$M$ & 6.31 & 6.13 & 5.38 & 5.36 & 4.74 & 3.15 & 2.56 & 2.33 \\
$(S D)$ & $(1.75)$ & $(2.03)$ & $(1.76)$ & $(1.58)$ & $(1.60)$ & $(1.63)$ & $(1.58)$ & $(2.11)$ \\
\hline
\end{tabular}




\section{Discussion}

Many studies have highlighted the importance of taking diverse social and cultural contexts into account when studying socialization processes in the family environment, since the values, socialization goals, beliefs, attitudes and activities that parents promote during interactions with their children are influenced by the cultural patterns and models of the society in which they live [47,48]. This issue becomes particularly relevant in relation to parenting support programs, since interventions that are valid for one culture may not be for another. Parenting support programs should be sensitive to cultural differences and should take the parenting cultural knowledge of participating families into account during implementation.

With the aim of optimizing family interventions aimed at ensuring sustainable parenting, the present study compared cultural beliefs in Spain and Peru about child and adolescent needs, the functions of the family and school contexts and the value of childhood and adolescence for society. Overall, the results reveal many similarities between the two countries in the explored topics, most likely due to the fact that both have strongly collectivist cultures $[20,21]$. Nevertheless, the comparison did reveal certain differences which, consistently with that reported by other authors, indicate the need to adapt family intervention programs to the existing cultural diversity [42,49-51].

Both cultures identified growing up in environments in which they feel loved and protected as the principal need of children and adolescents. The intra-country analyses revealed differences between the need of feel loved and the rest of the needs in both countries. These findings are consistent with that confirmed by attachment theorists, namely that establishing adequate affective bonds is a basic need in all cultures, even though it may manifest differently in accordance with socialization and relationship styles [52]. Furthermore, and as stated earlier [25,26], Peruvian and Spanish cultures both follow the autonomous-related model, characterized, among other things, by the emotional dependence of family members. In the Spanish culture, the need for children to have clear and consistent behavioral rules was found to be more important than in Peru, while Peruvian experts ranked growing up healthy and going to (and staying in) school more highly. These differences may be explained by the way in which the different child protection systems work in the two countries. The fact that, in Spain, the child protection system guarantees the care and wellbeing of minors more effectively than in Peru may explain the differences observed between the two cultures in terms of child and adolescent needs. In Peruvian society, children are a very vulnerable group and it is only to be expected that families in that culture will prioritize basic needs such as health and schooling, which are guaranteed to a greater extent in Spain [53].

Both cultures identified protecting and caring for children and adolescents as the principal function of the family context-results that were confirmed by both the inter- and intra-country comparisons. This result is consistent with studies that show the challenges involved in exercising positive parenting during adolescence. Since parents perceive that the protection and healthy growth of their children are the main functions of the family, the problems that some adolescents experience (related to alcohol use, for example) can make difficult both educational practices and the perception of parental competence [54]. In addition to the similarities found, the comparison between the two countries revealed that Peruvian culture values the family as the environment responsible for ensuring that children grow up healthy and strong, while in Spain, greater importance is attached to the role of the family as a socialization scenario and a context for promoting strategies for enabling children to think and reason in a richer, more complex manner. Here again, the differences observed between beliefs about child-rearing and development in Peru and Spain may be linked to cultural factors. As mentioned earlier, Peruvian families attach greater importance than their Spanish counterparts to the basic functions of care. However, when children's wellbeing and healthy physical development are guaranteed, as generally occurs in Spanish society, the family is perceived as being responsible for other tasks linked to needs of lesser priority, such as socialization and intellectual development [40].

The principal function of the school context in both cultures was the role played by schools as environments for stimulating child and adolescent development (intelligence, personality, etc.), 
and both agreed also that the least important function was that of providing protection and care. These results were confirmed by both the inter- and intra-country comparisons. Despite the progress that has been made in bringing families and schools closer together, the results of the study reveal how the functions of these two contexts are still perceived as very different, with families being responsible for caring for and protecting children, and schools being tasked with imparting instrumental and academic contents [55]. This distinction between the functions assigned to the family and school contexts clashes with current trends in psychopedagogy, which advocate reciprocal relationships based on participation and the opening up of both environments to the community, with the aim of boosting children's sustainable development [56].

The inter- and intra-comparisons revealed that both Spanish and Peruvian cultures coincide in their choice of the principal values of childhood and adolescence for society, identifying the stage as a particularly vulnerable one which is important for the future of society. Moreover, both societies also highlight adults' moral duty to ensure children's wellbeing through parenting and socialization practices geared towards promoting sustainable development. In this sense, parents from both cultures seem to have high expectations regarding their ability to influence their children's development, as indeed has been observed by other authors among families from North America and Central Europe, in contrast to those from developing countries [32,35]. This may prove decisive in terms of motivating parents to attend and actively participate in the psychoeducational and group programs currently run by the public authorities for families within the framework of positive parenting [57,58], and which may be particularly relevant for those parents who are unaware of the contextual keys of the society in which they are bringing up their children.

Although, as shown by the results of this study, it is very important to consider how culture influences beliefs about child-rearing and development, this issue cannot be analyzed in an isolated manner. Rather, the role of culture must be interpreted in relation to other contextual and personal variables which were not taken into account here. Thus, one conceptual limitation of the present study is the fact that it did not explore the interaction between cultural beliefs and other contextual, family and individual characteristics. Moreover, the results should be interpreted with caution since, at a methodological level, the study design did not take into account the fact that Peru encompasses over fifty different native peoples and nationalities, distributed across the coast, mountain and jungle regions. Each of these communities has its own cultural and sociological baggage and world view, all of which are very valuable and form the basis of their unique identities.

Despite these limitations, however, the practical implications of the study for the cultural adaptation of parenting support programs are highly relevant. It is vital to take the cultural differences highlighted by this study into account when optimizing family support programs aimed at ensuring the sustainable development of children from Peruvian families living in Spain, since in order to be effective, such interventions should recognize and respect cultural pluralism and diversity [42]. Likewise, this study provides very relevant information to know, in detail, the beliefs and values about development and education, both in Spain and Peru. Families constitute an increasingly less predictable environment subject to fast-paced social and cultural changes that impact both family functioning in general and parenting cultural knowledge in particular [18]. Firstly, Peruvian families settling in Spain must receive support for reorienting their parenting practices towards a scenario in which basic health and education needs are effectively covered for all minors. In this sense, the results of this study seem to support the incorporation of two main contents: the establishment of rules and limits for children by their parents, and the setting up of collaboration mechanisms with schools to enable the generation of a joint scenario for children's development. In addition to taking into account cultural differences in parental beliefs, it is essential to consider the results of studies comparing parenting in different countries, in order to identify the best practices and styles of socialization. In this sense, parenting support programs should consider the particular beliefs and values of each culture, as well as the parental practices that have proven to be the most appropriate for promoting the adjustment and the well-being of both children and adolescents. In particular, as noted in the introduction, available data indicate that parenting based 
on warmth and reasoning has a positive impact on healthy development, both in Spain and in South American countries $[17,19,59]$. Those responsible for designing family support programs should reflect on the functions of the school and the family for sustainable child development, and interventions should strive to strengthen the connections between families, schools and the broader community, in order to promote a greater awareness of education as a shared responsibility [55]. This implies that both families and teachers should rethink how they conceive the relationship between themselves and the environment, becoming what Slee [56] calls "cultural vigilantes"; meaning that they should be aware of the difficulties that may arise at each moment and in each social and cultural scenario, in order to avoid inadvertently falling into ways and thinking and acting that are not adapted to the cultural scenario, due to not being deemed useful or considered as going against predominant patterns.

The design and implementation of intervention programs with families must rise to three main challenges in order to respond to the needs of current family environments, which are characterized by diversity and change. Firstly, they should take into account the gap that many families encounter between what they learned from the previous generation and the needs of the generation they are tasked with raising. Today more than at any other moment in history, wide-ranging and deep-rooted changes are taking place which exacerbate the differences between what each generation considers appropriate and/or necessary for its members [10]. Secondly, they should, among other factors that make up this heterogeneous scenario, contemplate cultural origin and the intermingling of cultures, since, as stated earlier, parenting cultural knowledge is linked to that which is known and valued by each culture, in accordance with individual needs and desires [15]. Finally, these interventions should be considered a special form of working with migrant families, who are forced to combine expectations of what it means to be a parent in their culture of origin with expectations and demands associated with parenting roles in their host culture, with the resulting impact this may have on their parenting style [37]. This study aims to address this last challenge by trying to support families faced with the complex task of raising their children, in a cultural scenario which is different from the one in which they themselves were raised.

Author Contributions: Conceptualization, J.S., V.H. and I.L.-V.; formal analysis, L.J.; investigation, J.S., V.H. and L.J.; supervision, J.S., V.H., I.L.-V. and L.J.; methodology, J.S. and L.J.; writing-original draft, J.S., V.H., I.L.-V. and L.J.; writing-review and editing, J.S., V.H., I.L.-V. and L.J. All authors have read and agreed to the published version of the manuscript.

Funding: This research was partially funded by the Spanish Government (MINECO, Ministerio de Economía y Competitividad), grant number EDU2013-41441-P.

Conflicts of Interest: The authors declare no conflict of interest.

\section{References}

1. Daelmans, B.; Darmstadt, G.L.; Lombardi, J.; Black, M.M.; Britto, P.R.; Lye, S.; Dua, T.; Bhutta, Z.A.; Richter, L. Lancet early childhood development series steering committee early childhood development: The foundation of sustainable development. Lancet 2017, 389, 9-11. [CrossRef]

2. Ponzetti, J.J. Evidence-Based Parenting Education: A Global Perspective; Routledge/Taylor \& Francis Group: New York, NY, USA, 2016.

3. Van Ryzin, M.J.; Kumpfer, K.L.; Fosco, G.M.; Greenberg, M.T. Family-Based Prevention Programs for Children and Adolescents: Theory, Research, and Large-Scale Dissemination; Psychology Press: New York, NY, USA, 2016.

4. Tomlinson, M.; Bornstein, M.H.; Marlow, M.; Swartz, L. Imbalances in the knowledge about infant mental health in rich and poor countries: Too little progress in bridging the gap. Child Adolesc. Soc. Work. J. 2014, 35, 624-629. [CrossRef] [PubMed]

5. Kumpfer, K.L.; Pinyuchon, M.; De Melo, A.T.; Whiteside, H.O. Cultural adaptation process for international dissemination of the strengthening families program. Eval. Health Prof. 2008, 31, 226-239. [CrossRef] [PubMed]

6. Cauce, A.M. Parenting, culture, and context: Reflections on excavating culture. Appl. Dev. Sci. 2008, 12, 227-229. [CrossRef] 
7. Boyd, R.; Richerson, P.J. Solving the puzzle of human cooperation. In Evolution and Culture; Levinson, S., Ed.; MIT Press: Cambridge, MA, USA, 2005; pp. 105-132.

8. Smetana, J.G. Current research on parenting styles, dimensions, and beliefs. Curr. Opin. Psychol. 2017, 15, 19-25. [CrossRef]

9. Bornstein, M.H.; Yu, J.; Putnick, D.L. Mothers' parenting knowledge and its sources in five societies: Specificity in and across Argentina, Belgium, Italy, South Korea, and the United States. Int. J. Behav. Dev. 2019, 44, 135-145. [CrossRef]

10. Grusec, J.E.; Davidov, M. Analyzing socialization from a domain-specific perspective. In Handbook of Socialization: Theory and Research; Grusec, J.E., Hastings, P.D., Eds.; Guilford Press: New York, NY, USA, 2015; Volume 1, pp. 158-181.

11. Fuentes, M.C. Which is the best parenting style? Explaining the discrepancies across cultural influences. In Parenting-Cultural Influences and Impact on Childhood Health and Well-Being; García, F., Ed.; Nova Publishers: New York, NY, USA, 2015; pp. 1-16.

12. García, F.; Fernandéz-Doménech, L.; Veiga, F.H.; Bono, R.; Serra, E.; Musitu, G. Parenting styles and parenting practices: Analyzing current relationships in the Spanish context. In Parenting-Cultural Influences and Impact on Childhood Health and Well-Being; García, J.F., Ed.; Nova Publishers: New York, NY, USA, 2015; pp. 17-31.

13. Harkness, S. Explorations in culture and human development. Contemp. Psychol. 2000, 45, 106-108. [CrossRef]

14. Bornstein, M.H.; Lansford, J.E. Culture and family functioning. In APA Handbook of Contemporary Family Psychology: Applications and Broad Impact of Family Psychology; Fiese, B.H., Celano, M., Deater-Deckard, K., Jouriles, E.N., Whisman, M.A., Eds.; American Psychological Association: Washington, DC, USA, 2019; Volume 2, pp. 417-436.

15. Bornstein, M.H.; Putnick, D.L.; Suwalsky, J.T.D. Parenting cognitions $\rightarrow$ parenting practices $\rightarrow$ child adjustment? The standard model. Dev. Psychopathol. 2017, 30, 399-416. [CrossRef]

16. Fuentes, M.C.; Garcia, F.; Gracia, E.; Alarcon, A. Parental socialization styles and psychological adjustment. a study in spanish adolescents // Los estilos parentales de socialización y el ajuste psicológico. Un estudio con adolescentes españoles. Rev. Psicodidáctica 2014, 20, 117-138. [CrossRef]

17. Garcia, F.; Serra, E.; Garcia, O.F.; Martínez, I.; Cruise, E. A third emerging stage for the current digital society? Optimal parenting styles in Spain, the United States, Germany, and Brazil. Int. J. Environ. Res. Public Health 2019, 16, 2333. [CrossRef]

18. Licona, J.F.M.; Rodrigo, M.I.G.; Martínez, J.C.C. Modelos parentales en el contexto urbano: Un estudio exploratorio. Rev. Electrónica Investig. Educ. 2017, 19, 54. [CrossRef]

19. Martínez, I.; Garcia, F.; Veiga, F.H.; Garcia, O.F.; Rodrigues, Y.; Serra, E. Parenting styles, internalization of values and self-esteem: A cross-cultural study in Spain, Portugal and Brazil. Int. J. Environ. Res. Public Health 2020, 17, 2370. [CrossRef] [PubMed]

20. Bornstein, M.H. Parenting in acculturation: Two contemporary research designs and what they tell us. Curr. Opin. Psychol. 2017, 15, 195-200. [CrossRef]

21. Cabrera, N.J.; Shannon, J.D.; West, J.; Brooks-Gunn, J. Parental interactions with latino infants: Variation by country of origin and english proficiency. Child Dev. 2006, 77, 1190-1207. [CrossRef] [PubMed]

22. Yaman, A.; Mesman, J.; Van Ijzendoorn, M.H.; Bakermans-Kranenburg, M.J.; Linting, M. Parenting in an individualistic culture with a collectivistic cultural background: The Case of Turkish immigrant families with toddlers in the Netherlands. J. Child Fam. Stud. 2010, 19, 617-628. [CrossRef] [PubMed]

23. Fuentes, M.C.; García-Ros, R.; Pérez-González, F.; Sancerni, D. Effects of parenting styles on self-regulated learning and academic stress in spanish adolescents. Int. J. Environ. Res. Public Health 2019, 16, 2778. [CrossRef]

24. Alonso-Geta, M.P.P. La socialización parental en padres españoles con hijos de 6 a 14 años [Parenting socialization in Spanish caregivers of children from 6 to 14 years]. Psicothema 2012, 24, 371-376.

25. Keller, H.; Lamm, B.; Abels, M.; Yovsi, R.D.; Borke, J.; Jensen, H.; Papaligoura, Z.; Holub, C.; Lo, W.; Tomiyama, A.J.; et al. Cultural models, socialization goals, and parenting ethnotheories. J. Cross-Cultural Psychol. 2006, 37, 155-172. [CrossRef]

26. Greenfield, P.M.; Keller, H.; Fuligni, A.; Maynard, A. Cultural pathways through universal development. Annu. Rev. Psychol. 2003, 54, 461-490. [CrossRef]

27. Kast, M.J.; Farkas, C.; Vallotton, C.D. Diferencias en sensibilidad parental entre madres y padres de Chile y U.S.A. Psicoperspectivas. Individ. Soc. 2017, 16, 137-148. [CrossRef] 
28. Lansford, J.E.; Deater-Deckard, K. Childrearing discipline and violence in developing countries. Child Dev. 2012, 83, 62-75. [CrossRef] [PubMed]

29. Taverna, L.; Bornstein, M.H.; Putnick, D.L.; Axia, G. Adaptive behaviors in young children: A unique cultural comparison in Italy. J. Cross-Cultural Psychol. 2011, 42, 445-465. [CrossRef] [PubMed]

30. Bornstein, M.H.; Cote, L.R.; Haynes, O.M.; Suwalsky, J.T.D.; Bakeman, R. Modalities of infant-mother interaction in Japanese, Japanese American immigrant, and European American dyads. Child Dev. 2012, 83, 2073-2088. [CrossRef] [PubMed]

31. Bornstein, M.H. On the significance of social relationships in the development of children's earliest symbolic play: An ecological perspective. In Play and Development: Evolutionary, Sociocultural, and Functional Perspectives; Goncu, A., Gaskins, S., Eds.; Erlbaum: New York, NY, USA, 2007; pp. 101-129.

32. Bugental, D.B.; Ellerson, P.C.; Lin, E.K.; Rainey, B.; Kokotovic, A.; O'Hara, N. A cognitive approach to child abuse prevention. J. Fam. Psychol. 2002, 16, 243-258. [CrossRef]

33. Bornstein, M.H.; Putnick, D.L.; Cote, L.R.; Haynes, O.M.; Suwalsky, J.T.D. Mother-infant contingent vocalizations in 11 countries. Psychol. Sci. 2015, 26, 1272-1284. [CrossRef]

34. Lansford, J.E.; Sharma, C.; Malone, P.S.; Woodlief, D.; Dodge, K.A.; Oburu, P.O.; Pastorelli, C.; Skinner, A.T.; Sorbring, E.; Tapanya, S.; et al. Corporal punishment, maternal warmth, and child adjustment: A longitudinal study in eight countries. J. Clin. Child Adolesc. Psychol. 2014, 43, 670-685. [CrossRef]

35. Putnick, D.L.; Bornstein, M.H.; Lansford, J.E.; Chang, L.; Deater-Deckard, K.; Di Giunta, L.; Gurdal, S.; Dodge, K.A.; Malone, P.S.; Oburu, P.O.; et al. Agreement in mother and father acceptance-rejection, warmth, and hostility/rejection/neglect of children across nine countries. Cross-Cultural Res. 2012, 46, 191-223. [CrossRef]

36. Bornstein, M.H.; Bohr, Y. Immigration, acculturation and parenting. In Encyclopedia of Early Childhood Development; Tremblay, R.E., Boivin, M., Peters, R.d.V., Eds.; Center of Excellence for Early Childhood Development: Otawa, ON, Canada, 2011; Available online: http://www.child-encyclopedia.com/sites/ default/files/textes-experts/en/664/immigration-acculturation-and-parenting.pdf. (accessed on 10 May 2020).

37. Gallardo, A.N. Parental acculturation: A review of the challenges and adjustments that the process of acculturation implies in parental cognitions. Summa Psicológica UST 2019, 16, 121-129. [CrossRef]

38. De Haan, M. The Reconstruction of parenting after migration: A perspective from cultural translation. Hum. Dev. 2011, 54, 376-399. [CrossRef]

39. Aruj, R. Causas, consecuencias, efectos e impacto de las migraciones en Latinoamérica [Causes, consequences, effects and impact of migration in Latin America]. Pap. Poblac. 2009, 14, 95-116.

40. Maldonado, C.; Martínez, J.; Martínez, R. Una Mirada desde las Vulnerabilidades a lo Largo del Ciclo de la Migración y de la Vida de las Personas [A Vulnerabilities Sight throughout the Cycle of Migration and People's Lives]; CEPAL: Santiago, Chile, 2018.

41. Instituto Nacional de Estadística. Estadística de Migraciones [Migration Statistics]; INE: Madrid, Spain, 2020. Available online: https://www.ine.es/dyngs/INEbase/es/categoria.htm?c=Estadistica_P\&cid=1254735573002 (accessed on 14 June 2020).

42. Van Mourik, K.; Crone, M.R.; De Wolff, M.S.; Reis, R. Parent training programs for ethnic minorities: A meta-analysis of adaptations and effect. Prev. Sci. 2016, 18, 95-105. [CrossRef] [PubMed]

43. Delbecq, A.L.; Van de Ven, A.H.; Gustafson, D.H. Group Techniques for Program Planning: A Guide to Nominal Group and Delphi Processes; Scott Forman and Co.: Glenview, IL, USA, 1975.

44. AERA, APA \& NCME. Standards for Educational and Psychological Tests; American Psychological Association, American Educational Research Association, National Council on Measurement in Education: Washington, DC, USA, 1999.

45. Hsu, C.C.; Sandford, B.A. The Delphi technique: Making sense of consensus. Pract. Assess. Res. Eval. 2007, 12, 1-8.

46. Ulschak, F.L. Human Resource Development: The Theory and Practice of Need Assessment; Reston Publishing Company, Inc.: Reston, VA, USA, 1983.

47. Bornstein, M.H. Cultural approaches to parenting. Parent. Sci. Pract. 2012, 12, 212-221. [CrossRef] [PubMed]

48. September, S.J.; Rich, E.G.; Roman, N. The role of parenting styles and socio-economic status in parents' knowledge of child development. Early Child Dev. Care 2015, 186, 1060-1078. [CrossRef]

49. Musitu, G.; García, J.F. Consecuencias de la socialización familiar en la cultura española [Consequences of family socialization in the Spanish culture]. Psicothema 2004, 16, 288-293. 
50. Taraban, L.; Shaw, D.S. Parenting in context: Revisiting Belsky's classic process of parenting model in early childhood. Dev. Rev. 2018, 48, 55-81. [CrossRef]

51. Steiker, L.K.H.; Castro, F.G.; Kumpfer, K.; Marsiglia, F.F.; Coard, S.; Hopson, L.M. A dialogue regarding cultural adaptation of interventions. J. Soc. Work. Pract. Addict. 2008, 8, 154-162. [CrossRef]

52. Keller, H. Attachment and culture. J. Cross-Cultural Psychol. 2012, 44, 175-194. [CrossRef]

53. Rubio, M. La Construcción de un Sistema de Protección Social Adecuado a la Infancia en Perú. Oportunidades y Retos [The Construction of an Adequate Social Protection System for Children in Peru. Opportunities and Challenges]; CEPAL: Santiago, Chile, 2017.

54. Garcia, O.F.; Serra, E.; Zacares, J.J.; Calafat, A.; Garcia, F. Alcohol use and abuse and motivations for drinking and non-drinking among Spanish adolescents: Do we know enough when we know parenting style? Psychol. Health 2019, 35, 645-664. [CrossRef]

55. Simón, C.; Giné, C.; Sarrionandia, G.E. Escuela, familia y comunidad: Construyendo alianzas para promover la inclusión. Rev. Latinoam. Educ. Inclusiva 2016, 10, 25-42. [CrossRef]

56. Slee, R. La Escuela Extraordinaria. Exclusión, Escolarización y Educación Inclusiva [The Extraordinary School. Exclusion, Schooling and Inclusive Education]; Morata: Madrid, Spain, 2012.

57. Jiménez, L.; Hidalgo, V. La incorporación de prácticas basadas en evidencias en el trabajo con familias: Los programas de promoción de parentalidad positiva [The inclusion of evidence-based practices in family support: Positive parenting programs]. Apunt. Psicol. 2016, 34, 91-100.

58. Rodrigo, M.J.; Almeida, A.Y.; Reichle, B. Evidence-based parent education programs: A European perspective. In Evidence-Based Parenting Education: A Global Perspective; Ponzetti, J., Ed.; Routledge: New York, NY, USA, 2016; pp. 85-104.

59. Pinquart, M.; Kauser, R. Do the associations of parenting styles with behavior problems and academic achievement vary by culture? Results from a meta-analysis. Cult. Divers. Ethn. Minor. Psychol. 2018, 24, 75-100. [CrossRef] [PubMed]

(C) 2020 by the authors. Licensee MDPI, Basel, Switzerland. This article is an open access article distributed under the terms and conditions of the Creative Commons Attribution (CC BY) license (http://creativecommons.org/licenses/by/4.0/). 